\title{
Radical therapy of resectable and borderline resectable pancreatic cancer - present state of knowledge. Do we have sufficient data to use neoadjuvant treatment?
}

\section{Radykalne leczenie resekcyjnych i granicznie resekcyjnych raków trzustki - obecny stan wiedzy. Czy mamy wystarczające dane, by stosować leczenie neoadiuwantowe?}

\author{
Robert Dziura1 ${ }^{\text {, Paweł Macek }}{ }^{2,3}$, Jolanta Smok-Kalwat', Stanisław Góźdźn ${ }^{1,2}$ \\ 'Department of Clinical Oncology, Holy Cross Cancer Center, Kielce, Poland \\ Head of the Department: Prof. Stanisław Góźdź MD, PhD \\ ${ }^{2}$ Collegium Medicum, Jan Kochanowski University, Kielce, Poland \\ Head of the Collegium: Prof. Marianna Janion MD, PhD \\ ${ }^{3}$ Department of Epidemiology and Cancer Control, Holy Cross Cancer Centre, Kielce, Poland \\ Head of the Department: Paweł Macek MD, PhD
}

Key words: pancreatic cancer, neoadjuvant treatment, chemotherapy.

Słowa kluczowe: rak trzustki, leczenie przedoperacyjne, chemioterapia.

\begin{abstract}
The incidence of pancreatic cancer has been increasing in recent years. It is expected to be the second or the third leading cause of cancer deaths in high-income countries in the next decade. Standard therapeutic management for patients with resectable pancreatic cancer is surgical resection followed by adjuvant chemotherapy. The main reason for neoadjuvant therapy is that the prognosis with current strategies is unsatisfactory, and we need new treatments to improve overall survival as well as the quality of life of the patients suffering from pancreatic cancer. The aim of this paper is to provide an overview of the recent data on the subject of neoadjuvant treatment concerning resectable and borderline resectable group of patients.
\end{abstract}

\section{Streszczenie}

W ciągu ostatnich lat wzrasta zachorowalność na raka trzustki. Szacuje się, że w ciągu nadchodzącej dekady stanie się drugą lub trzecią przyczyną zgonów z powodu nowotworów w krajach rozwiniętych. Standardowe leczenie w stadium zlokalizowanym opiera się na radykalnej resekcji chirurgicznej z następczą chemioterapią adiuwantową. Głównym uzasadnieniem prowadzenia w ostatnich latach badań klinicznych nad zastosowaniem przedoperacyjnego leczenia systemowego są obecnie niezadowalające wyniki zarówno w zakresie całkowitego przeżycia, jak i jakości życia chorych. Celem pracy jest przedstawienie aktualnych danych dotyczących leczenia neoadiuwantowego pacjentów w stadium resekcyjnym i granicznie resekcyjnym raka trzustki.

\section{Introduction}

In $2018,458,918$ new cases of pancreatic cancer were registered worldwide, representing $2.5 \%$ of all cancers [1]. It is predicted that it will be the second leading cause of cancer death by 2030 due to the rising incidence and lack of effective preventive strategies [2]. The aetiopathogenesis of the disease remains unclear. Among various environmental risk factors, some, such as tobacco smoking, obesity, type 2 diabetes, cirrhosis, chronic pancreatitis and non-alcoholic liver disease, are indicated. To date, no gene has been discovered the damage of which could be specifically related to the cancer of this organ. However, several genetic mutations have been recognised that are involved in the development of pancreatic cancer, including BRCA2, PALB2, STK11, and low-penetration genes such as the blood group ABO locus [3].

Surgical resection is the only potentially curative treatment for pancreatic adenocarcinoma. Despite recent advances in the management of pancreatic cancer, long-term survival after curative surgery is disappointing. Even resectable tumours are associated with a high rate of recurrence. The 5-year sur- 
vival rate after surgical treatment alone is about $10 \%$, and 10 -year survival is $7.7 \%[2,4-6]$. The main reason for treatment failure these are distant metastases $(2 / 3$ cases). $69-75 \%$ of patients after resection for pancreatic cancer develop recurrence, within 2 years, and 80-90\% within 5 years. Despite major improvements in the palliative setting, in the case of metastatic and locally advanced nonresectable disease, only $1-3 \%$ of patients achieve 5-year survival [2, 4].

\section{Aim of the research}

The aim of this paper is to provide an overview of the recent data on the subject of neoadjuvant treatment concerning resectable and borderline resectable patients.

\section{Material and methods}

In order to analyse the results of the most recent randomised studies related to the neoadjuvant therapy a literature review was performed using the PubMed database by entering the following keywords and phrases: pancreatic cancer, neoadjuvant treatment, chemotherapy. We choose the latest meta-analyses, as well as trials that suggested a significant survival benefit from preoperative treatment. Although there is some subjectivity in our selection, we hope, this review provides the most relevant information and reliable data concerning neoadjuvant therapy for resectable and borderline resectable patients.

\section{Review of the literature}

\section{Criteria defining resectability status at diagnosis}

The standard treatment for patients with resectable tumour is surgical resection followed by adjuvant chemotherapy $[2,4,5]$. Selection of operable patients depends on the technical possibility of achieving microscopically negative resection margins. Only $10-20 \%$ of patients have resectable disease after diagnosis, but there are no clear-cut criteria to define R0 resectability in advance, partly because the imaging (CT or MRI) sensitivity and specificity are < 100\% [2].

Decisions about resectability status should be made in consensus at a multidisciplinary meeting. Surgery first should be performed only in the absence of clinical evidence of metastatic disease and at a performance status and comorbidity profile appropriate for major abdominal operations [4]. Resectable adenocarcinoma is defined by the absence of distant organ or distant lymph node metastases and no arterial tumour contact with the celiac axis, superior mesenteric artery, common hepatic artery. Additionally, the absence of contact with the superior mesenteric vein or portal vein, or venous encasement $>180^{\circ}$ $[4,5]$. Borderline resectable tumours comprise radio- logical criteria according to definitions of European and American guidelines: arterial contact $<180^{\circ}$ (celiac trunk, superior mesenteric artery, common hepatic artery), and venous contact $\geq 180^{\circ}$ without vein contour irregularity (superior mesenteric vein or portal vein) or $<180^{\circ}$ amenable to vein reconstruction $[4,5]$.

In case of high-risk features (highly elevated ca199, large primary tumours, large regional lymph nodes, excessive weight loss, extreme pain) staging laparoscopy should be considered [4].

\section{Adjuvant therapy}

Survival benefit was demonstrated with the addition of chemotherapy to curative intent pancreatectomy. Every patient, regardless of age, should receive adjuvant treatment for over 6 months after surgery [2].

The evolution of adjuvant chemotherapy started with the publication of the result of the four-arm ESPAC-1 trial. The benefit from the addition of systemic treatment was shown for patients treated using 6 months of fluorouracil after resection. Postoperative treatment increased the 5 -year survival rate $(21 \%$ vs. $8 \%$ ). The benefits of combined radiochemotherapy have not been documented [7].

In the subsequent randomised CONKO-001 trial, postoperative gemcitabine significantly delayed the development of recurrent disease after the complete resection of pancreatic cancer compared with the observation alone [8]. Long-term analysis of this trial showed that among patients with macroscopic complete removal of pancreatic cancer, the use of adjuvant gemcitabine for 6 months compared with the observation alone resulted in increased overall and diseasefree survival [9].

A consequence of the above results was a comparison of both cytostatics, which were evaluated in the ESPAC-3 trial. There was no superiority in overall survival in either arm, but tolerance and the percentage of adverse effects spoke in favour of gemcitabine, setting the standard of treatment at the time [10].

Further clinical trials aimed at assessing the efficacy of polychemotherapy use. The ESPAC-4 study proved the benefit of gemcitabine-capecitabine combination treatment, improving the 5-year survival rate from $16.3 \%$ to $28.8 \%$. The combination treatment arm achieved a median overall survival of 28 months, compared to gemcitabine alone at 25.5 months. An important aspect derived from the ESPAC-4 study was the subgroup analysis. R0 patients had a major advantage with the addition of capecitabine (OS 39.5 months vs. 27.9 months) and the lack of significant benefits from postoperative treatment for patients with microscopic margin-positive surgery (OS 23.7 months vs. 23 months) [11].

Additionally, the ESPAC-4 trial suggested that continuous adjuvant treatment in appropriate dose intensity is important for survival. When chemother- 
apy was given for the full 6 months there was no difference between the overall survival (OS) of patients with that of patients starting systemic treatment after 6-12 weeks postoperatively [2, 11].

In 2018, the results of the PRODIGE 24/CCTG trial were presented. In this multicentre international randomised phase III trial adjuvant multi-agent chemotherapy mFOLFIRINOX significantly improved disease-free survival (DFS), metastasis-free survival (MFS), and OS compared to gemcitabine alone. The median OS in patients randomised to receive a 24-weeks mFOLFIRINOX regimen was 54.4 months vs. median OS of 35.0 months in patients randomised to receive 24 weeks of single agent gemcitabine. Median DFS was 12.8 months vs. 21.6 months in favour of the mFOLFIRINOX arm. It is important to mention that patients enrolled in the trial were in good or very good condition, without significant comorbidities and with postoperative serum ca19-9 level $<180 \mathrm{U} / \mathrm{ml}$. The clinical benefit is associated with greater toxicity in the form of diarrhoea, neutropaenia and mucositis. Only $66 \%$ of patients received all cycles of chemotherapy despite of strict including patient selection. Thanks to the most favourable median overall survival, mFOLFIRINOX remains the present standard of adjuvant treatment for patients in good general condition, who tolerate the risk of greater toxicity. Intensive supportive care is needed [12].

Positive results of nab-paclitaxel treatment in the advanced stage of pancreatic cancer legitimise the assessment of the efficacy of chemotherapy in adjuvant combination therapy with gemcitabine in the phase III APACT study. Despite achieving about 40.5 months of overall survival in the experimental arm, the study did not demonstrate a significant difference in the primary end-point, which was to improve DFS (19.4 months vs. 18.8 months) [13].

\section{Neoadjuvant therapy}

Despite the documented benefits in terms of DFS and OS after adjuvant treatment, in recent years we have seen a growing amount of data for preoperative treatment in the case of borderline and even resectable cases $[14,15]$.

The implementation of the full adjuvant chemotherapy protocol may be limited for many reasons. The tolerance and toxicity of adjuvant treatment are worse than preoperative treatment. Patients may not be able to achieve proper nutritional status, and there is a high risk of postoperative complications. Approximately $25 \%$ patients will never receive adjuvant chemotherapy, and nearly half of them fail to complete full postoperative therapy [14-16].

Additionally, during primary surgery $17 \%$ of the patients are identified to have occult metastatic disease. Macroscopically radical surgery in many cases turns out to be $\mathrm{R} 1$ treatment. The $\mathrm{R} 0$ resection rate after upfront surgery differs among studies between $29 \%$ and $81 \%$. The patients who undergo R1 resection present a similar prognosis to that of locally advanced, inoperable tumour [16].

The possible presence of micrometastases, circulating tumour cells, and systemic disease from the outset supports the approach of neoadjuvant treatment [16].

Preoperative therapy could have better compliance and the potential to down-stage tumours and lymph nodes, and increase the $\mathrm{R} 0$ resection rate. The risk of disease progression during chemotherapy applies to approximately $20 \%$ of the patients. These patients are highly likely to have such an unfavourable prognosis that they would not benefit from surgery. Theoretically, the main risk could be the greater possibility of postoperative complications and worse prognosis as a result of postponing or disabling potential surgical treatment [16].

The aim of the meta-analysis published by the Dutch Pancreatic Cancer Group in 2018 was to report on the survival between neoadjuvant treatment in resectable or borderline resectable pancreatic cancer in comparison to up-front surgery. Thirty-eight studies were included with 3484 patients, of whom 1738 (49.9\%) had neoadjuvant treatment [17].

Overall survival by intention to treat analysis was 18.8 months for neoadjuvant treatment and 14.8 months for upfront surgery. Among the patients who underwent resection, the difference was larger, at 26.1 months vs. 15.0 months, respectively.

For 18 studies that included 857 patients with resectable pancreatic cancer after neoadjuvant treatment, the weighed median overall survival was 18.2 months.

The overall resection rate was lower in the patients who had neoadjuvant treatment rather than those who had upfront surgery (66.0\% vs. $81.3 \%)$; however, the $\mathrm{R} 0$ resection rate was higher both in ITT analysis (58\% vs. $54.9 \%$ ) and among the patients who underwent resection $(86.8 \%$ vs. $66.9 \%)$. The pathological lymph node rate was also improved in the neoadjuvant group (64.8\% vs. $43.8 \%)$.

All of the studies used at least chemotherapy as neoadjuvant treatment, usually including gemcitabine (26 studies). Radiotherapy was given as a part of the treatment in 29 studies.

Toxicity of at least grade III was reported in up to $64 \%$ of the patients, mostly involving leukopaenia, thrombocytopaenia, nausea and fatigue. $17.8 \%$ of the patients who had neoadjuvant treatment did not undergo any exploratory surgery. In the case of $64 \%$ of these patients progression of disease was the reason for avoiding surgery [17].

A meta-analysis published in December 2019 aimed to discover if there exists any survival benefit of neoadjuvant chemo(radio)therapy versus surgery first in patients with resectable or borderline resectable pancreatic cancer [18]. The meta-analysis includ- 
ed 17 comparative trials from 2011 to 2018 with 2286 participants and it demonstrates that neoadjuvant treatment can provide a survival benefit in borderline resectable patients and a subgroup of resectable patients. The OS was synthesised in the analysis of all patients (intention-to-treat (ITT) analysis) and the resected patients, respectively [18].

For resectable patients in the ITT population the OS analysis was similar $(\mathrm{HR}=1.02)$ between neoadjuvant treatment and surgery first. However, in the analysis of patients who undergo resection OS was higher with preoperative treatment $(\mathrm{HR}=0.75)$. The overall resection rate was lower, but the R0 rate was higher in the experimental arm.

For borderline resectable patients, significantly better OS was shown both in ITT analysis $(\mathrm{HR}=0.48)$ as well as in the analysis of resected patients $(\mathrm{HR}=0.66)$ in comparison to surgery first, with comparable overall resection rate. Disease-free survival, $\mathrm{R} 0$ rate, and recurrence were also in favour of the preoperative therapy.

For resected patients, neoadjuvant therapy remarkedly increased OS and 1-, 3-, and 5-year survival among primary resectable and borderline-resectable patients [18].

Although this meta-analysis demonstrates that preoperative treatment can provide survival benefits, some limitations of the present review must be taken into account. There are various treatment regimens in this meta-analysis, including multiple-agents, combined single-agent chemotherapy and radiotherapy, and combined multiple-agents chemotherapy and radiotherapy. Heterogeneity exists in chemotherapy regimens as well as in the radiotherapy dose. The majority of analysed studies were retrospective [18].

In June 2018, the preliminary results of the PREOPANC-1 randomised phase III trial were presented. In this trial, the efficacy of primary surgery and subsequent chemotherapy was compared with the neoadjuvant strategy in a group of borderline and resectable patients. Two hundred forty-six patients were randomised to two arms. Patients in the first arm received six cycles of gemcitabine after surgery. Patients in the second arm received two cycles of gemcitabine with subsequent chemoradiation (hypofractionated radiation scheme of 15 fractions of $2.4 \mathrm{~Gy}$, combined with gemcitabine based systemic therapy). Surgery was followed by four cycles of adjuvant gemcitabine [19].

In the ITT analysis, the group of patients with neoadjuvant strategy resection rate was smaller than in the immediate surgery group (62\% vs. $72 \%)$; however, a higher percentage of R0 resection procedures was achieved (65\% vs. 31\%). No significant difference was observed in grade $\geq 3$ adverse events between both groups.

The complete data and analyses have not been reported yet, although among the patients who underwent resection the preliminary results from the trial demonstrate OS benefit (29.9 months vs. 16.8 months) [19].
The comparison between neoadjuvant chemotherapy with gemcitabine and S-1 was evaluated in the Asian JSAP-05 randomised multi-institutional phase II/III trial. 364 resectable or borderline-resectable patients were enrolled from 57 institutions. The median OS for the perioperative group was 36.7 vs. 26.6 months in the adjuvant group ( $\mathrm{HR}=0.72)$, favouring perioperative therapy. Neoadjuvant treatment improved the 2-year OS rate from 52.5\% to $63.7 \%$. Operative morbidity between the two groups was equivalent. In both groups the $\mathrm{R} 0$ resection rate was found to be comparable [20].

In 2018, the results of a single-arm phase II clinical trial were published evaluating the benefit of total neoadjuvant treatment in borderline-resectable pancreatic cancer. Forty-eight patients received FOLFIRINOX for eight cycles. Clinical decisions were taken after subsequent restaging. The patients with resolution of vascular involvement received shortcourse chemoradiotherapy (5 Gy $\times 5$ with protons) with capecitabine. The patients with persistent vascular involvement received long-course chemoradiotherapy with fluorouracil or capecitabine. Among the 32 patients who underwent resection, the R0 resection rate was $97 \%$. Median PFS among all patients was 14.7 months; median OS was 37.7 months. Among the patients who underwent resection, median PFS was 48.6 months and median OS was not reached, with a 2-year PFS of 55\% and a 2-year OS of 72\% [21].

FOLFIRINOX is a standard treatment for adjuvant therapy as well as for locally advanced and metastatic pancreatic cancer patients. In 2019 a meta-analysis of borderline-resectable patients treated with neoadjuvant FOLFIRINOX showed favourable median OS, resection rate, and $\mathrm{R} 0$-resection rate. The metaanalysis on neoadjuvant FOLFIRINOX included 24 studies ( 8 prospective, 16 retrospective), comprising 313 patients. The resection rate was $67.8 \%$, and the R0-resection rate was $83.9 \%$. Patient-level median OS was 22.2 months, with a median progression-free survival of 18.0 months. The most common grade $3-4$ adverse events included neutropaenia (17.5\%), diarrhoea (11.1\%), and fatigue (10.8\%) [22].

\section{Summary}

According to pretherapeutic staging, up to $80 \%$ of patients with pancreatic cancer receive a diagnosis at an advanced stage and only $10-20 \%$ of them have resectable disease. The gold standard of radical treatment is pancreatoduodenectomy with adjuvant therapy; however, data from The Netherlands Cancer Registry revealed that only 54\% undergo adjuvant chemotherapy, because of toxicity, age or other factors [16]. The ability to improve the R0 rate with the use of neoadjuvant therapy is important because the negative margins are associated with better outcome. 
At present, recommendations for neoadjuvant therapy exist only for borderline-resectable and locally advanced tumours. The patients with radiological risk of R1 resection are not candidates for primary surgery; however, until now a preoperative treatment strategy has not been defined.

The presented meta-analyses are limited by the selection bias, including discrepancies in individual systemic treatment regimens as well as radiotherapy methods, which restrict the analysis of individual subgroups. The statistical analysis depends on heterogeneous groups of patients. Additionally, the treatments protocols included using or not using radiation therapy. If radiotherapy was administered, it may have been concurrent with chemotherapy or in a sequential protocol. The important limitations of the analysed trials are differences in the definition of resectability. Some potential benefits of the preoperative treatment of resectable patients can come at the cost of risk of tumour progression while waiting for the surgery [16-18]. Additional risk could be associated with the time for bile duct decompensation and the time for pathological confirmation [16-18, 23]. Most of the present data are reported from retrospective studies of mixed populations of resectable and borderline-resectable patients. Most of these trials are limited by small sample sizes. However, the majority of the data present consistent results, showing that preoperative treatment increases survival in borderline and resectable tumours $[17,18]$.

There is still a lack of strong scientific evidence supporting the theoretical advantages of neoadjuvant therapies. The randomised phase III studies comparing neoadjuvant treatment with upfront surgery are still necessary to provide evidence to determine a particular preoperative approach. Future research should look for potential biomarkers to screen the subgroup of resectable patients who can benefit from neoadjuvant therapy [24]. Under investigation there are several studies with neoadjuvant chemotherapy in resectable pancreatic adenocarcinoma [25-27]. More large-scale and well-designed trials are needed to answer the question of whether we should use chemotherapy alone or radiochemotherapy in the neoadjuvant treatment of pancreatic cancer. During the ASCO 2019 conference the first data from the SWOG1505 trial were presented. This was a randomised phase II trial analysing the benefit of perioperative chemotherapy with either mFOLFIRINOX or gemcitabine/ nab-paclitaxel for resectable pancreatic adenocarcinoma. To date, $77 \%$ of eligible patients (99) went to surgery and 73\% underwent resection. Eighty-four per cent of patients completed chemotherapy. In the case of patients who did not reach protocol surgery, $35 \%$ had progression of disease and $39 \%$ had chemotherapy related toxicity. The follow-up for overall survival is ongoing [28]. We hope ongoing randomised trials will provide some additional clinical data that could further define long-term efficacy of neoadjuvant strategies.

\section{Conflict of interest}

The authors declare no conflict of interest.

\section{References}

1. Rawla P, Sunkara T, Gaduputi V. Epidemiology of pancreatic cancer. Global trends, etiology and risk factors. World J Oncol 2019; 10: 10-27.

2. Ducreux M, Cuhna AS, Caramella C, Hollebecque A, Burtin P, Goéré D, Seufferlein T, Haustermans K, Van Laethem JL, Conroy T. Cancer of the pancreas: ESMO Clinical Practice Guidelines for diagnosis, treatment and follow-up. Ann Oncol 2015; 26: 56-68.

3. Głuszek S, Kozieł D. Genetic determination of pancreatic cancer. Medical Studies 2018; 34: 178-182.

4. Tempero M, Malafa M, Chiorean E, Czito B, Scaife C, Narang A, Fountzilas C, Wolpin BM, Al-Hawary M, Asbun H, Behrman SW, Benson AB, Binder E, Cardin DB, Cha CH, Chung V, Dillhoff M, Dotan E, Ferrone CR, Fisher G, Hardacre J, Hawkins WG, Ko AD, LoConte N, Lowy AM, Moravek C, Nakakura EK, O'Reilly EM, Obando J, Reddy S, Thayer S, Wolff RA, Burns JL, Zuccarino-Catania G. NCCN Guidelines Insights: Pancreatic Adenocarcinoma Version 1.2019 Journal of the National Comprehensive Cancer Network 2019; 17: 202-210.

5. Khorana AA, Mangu P, Berlin J, Engebretson A, Hong TS, Maitra A, Mohile SG, Mumber M, Schulick M, Shapiro M, Urba S, Zeh HJ, Katz MHG. Potentially curable pancreatic cancer: American Society of Clinical Oncology clinical practice guideline update. J Clin Oncol 2017; 35: 2324-2328.

6. Wyrwicz L. Rak trzustki Kompendium. Medical Education, Warsaw, 2018.

7. Neoptolemos JP, Stocken DD, Friess H, Bassi C, Dunn JA, Hickey H, Beger H, Fernandez-Cruz L, Dervenis C, Lacaine F, Falconi M, Pederzoli P, Pap A, Spooner D, Kerr DJ, Büchler MW. A randomized trial of chemoradiotherapy and chemotherapy after resection of pancreatic cancer. N Engl J Med 2004; 350: 1200-1210.

8. Oettle H, Post S, Neuhaus P, Gellert K, Langrehr J, Ridwelski K, Schramm H, Fahlke J, Zuelke C, Burkart C, Gutberlet K, Kettner E, Schmalenberg H, Weigang-Koehler K, Bechstein WO, Niedergethmann M, Schmidt-Wolf I, Roll L, Doerken B, Riess H. Adjuvant chemotherapy with gemcitabine vs observation in patients undergoing curative-intent resection of pancreatic cancer: a randomized controlled trial. JAMA 2007; 297: 267-77.

9. Oettle H, Neuhaus P, Hochhaus A, Hartmann JT, Gellert K, Ridwelski K, Niedergethmann M, Zülke C, Fahlke J, Arning MB, Sinn M, Hinke A, Riess H. Adjuvant chemotherapy with gemcitabine and long-term outcomes among patients with resected pancreatic cancer: the CONKO-001 randomized trial. JAMA 2013; 310: 1473-1481.

10. Neoptolemos JP, Stocken DD, Bassi C, Ghaneh P, Cunningham D, Goldstein D, Padbury R, Moore MJ, Gallinger S, Mariette C, Wente MN, Izbicki JR, Friess $H$, Lerch MM, Dervenis C, Oláh A, Butturini G, Doi R, Lind PA, Smith D, Valle JW, Palmer DH, Buckels JA, Thompson J, McKay CJ, Rawcliffe CL, Büchler MW. Adjuvant chemotherapy with fluorouracil plus folinic acid vs gemcitabine following 
pancreatic cancer resection: a randomized controlled trial. JAMA 2010; 304: 1073-1081.

11. Neoptolemos JP, Palmer DH, Ghaneh P, Psarelli EE, Valle JW, Halloran CM, Faluyi O, O’Reilly DA, Cunningham D, Wadsley J, Darby S, Meyer T, Gillmore R, Anthoney A, Lind P, Glimelius B, Falk S, Izbicki JR, Middleton GW, Cummins S, Ross PJ, Wasan H, McDonald A, Crosby T, Ma YT, Patel K, Sherriff D, Soomal R, Borg D, Sothi S, Hammel P, Hackert T, Jackson R, Büchler MW. Comparison of adjuvant gemcitabine and capecitabine with gemcitabine monotherapy in patients with resected pancreatic cancer (ESPAC-4): a multicentre, open-label, randomised, phase 3 trial. Lancet 2017; 389: 1011-1024.

12. Conroy T, Hammel P, Hebbar M, Ben Abdelghani M, Wei AC, Raoul JL, Choné L, Francois E, Artru P, Biagi JJ, Lecomte T, Assenat E, Faroux R, Ychou M, Volet J, Sauva net A, Breysacher G, Di Fiore F, Cripps C, Kavan P, Texereau P, Bouhier-Leporrier K, Khemissa-Akouz F, Le goux JL, Juzyna B, Gourgou S, O’Callaghan CJ, Jouffroy-Zeller C, Rat P, Malka D, Castan F, Bachet JB. FOLFIRINOX or gemcitabine as adjuvant therapy for pancreatic cancer. N Engl J Med 2018; 379: 2395-2406.

13. Tempero MA, Reni M, Riess H, Pelzer U, O’Reilly EM, Winter JM, Oh D, Li ChP, Tortora G, Chang HG, Lopez Ch, Tabernero J, Van Cutsem E, Philip AF, Goldstein D, Berlin J, Ferrara S, Li M, Lu BD, Biankin A. APACT: phase III, multicenter, international, open-label, randomized trial of adjuvant nab-paclitaxel plus gemcitabine (nab-P/G) vs gemcitabine $(\mathrm{G})$ for surgically resected pancreatic adenocarcinoma. J Clin Oncol 2019; 37 (15 Suppl): 4000.

14. Álvarez R, Alés I, Díaz R, de Paredes BG, Hidalgo M. Neoadjuvant treatment for borderline and resectable pancreatic ductal adenocarcinoma. Clin Transl Oncol 2017; 19 1193-1198.

15. Li Lim KH, Chung E, Khan A, Cao D, Linehan D, Ben-Josef E, Wang-Gillam A. Neoadjuvant therapy of pancreatic cancer: the emerging paradigm? Oncologist 2012; 17: 192-200.

16. Lambert A, Schwarz L, Borbath I, Henry A, Van Laethem JL, Malka D, Ducreux M, Conroy T. An update on treatment options for pancreatic adenocarcinoma. Ther Adv Med Oncol 2019; 11: 1758835919875568.

17. Versteijne E, Vogel JA, Besselink MG, Busch ORC, Wilmink JW, Daams JG, van Eijck CHJ, Groot Koerkamp B, Rasch CRN, van Tienhoven G. Meta-analysis comparing upfront surgery with neoadjuvant treatment in patients with resectable or borderline resectable pancreatic cancer. Br J Surg 2018; 105: 946-958.

18. Pan L, Fang J, Tong C, Chen M, Zhang B, Juengpanich S, Wang Y, Cai X. Survival benefits of neoadjuvant chemo(radio)therapy versus surgery first in patients with resectable or borderline resectable pancreatic cancer: a systematic review and meta-analysis. World J Surg Oncol 2019; doi: 10.1186/s12957-019-1767-5.

19. Van Tienhoven G, Versteijne E, Suker M, Groothuis K, Busch O, Bonsing BA, de Hingh IHJT, Festen S, Patijn GA, de Vos-Geelen J, Zwinderman AH, Punt CJA, van Eijck $\mathrm{CHJ}$. Preoperative chemoradiotherapy potentially improves outcome for (borderline) resectable pancreatic cancer: preliminary results of the Dutch randomized phase III PREOPANC trial. J Clin Oncol 2020; 38: 1763-1773.

20. Unno M, Motoi F, Matsuyama Y, Satoi S, Matsumoto I, Aosasa S, Shirakawa H, Wada K, Fujii T, Yoshitomi H, Takahashi S, Sho M, Ueno H, Kosuge T. Randomized phase II/III trial of neoadjuvant chemotherapy with gemcita- bine and S-1 versus upfront surgery for resectable pancreatic cancer (Prep-02/JSAP05). J Clin Oncol 2019; 34 (4 Suppl): 189

21. Murphy JE, Wo JY, Ryan DP, Jiang W, Yeap BY, Drapek LC, Blaszkowsky LS, Kwak EL, Allen JN, Clark J, Faris JE, Zhu AX, Goyal L, Lillemoe DeLaney, Fernández-Del Castillo C, Ferrone C, Hong T. Total neoadjuvant therapy with FOLFIRINOX followed by individualized chemoradiotherapy for borderline resectable pancreatic adenocarcinoma: a phase 2 clinical trial. JAMA Oncol 2018; 4: 963-969.

22. Janssen QP, Buettner S, Suker M, Beumer BR, Addeo P, Bachellier P, Bahary N, Bekaii-Saab T, Bali MA, Besselink MG, Boone BA, Chau I, Clarke S, Dillhoff M, ElRayes BF, Frakes JM, Grose D, Hosein PJ, Jamieson NB, Javed AA, Khan K, Kim KP, Kim SC, Kim SS, Ko AH, Lacy J, Margonis GA, McCarter MD, McKay CJ, Mellon EA, Moorcraft SY, Okada KI, Paniccia A, Parikh PJ, Peters NA, Rabl H, Samra J, Tinchon C, van Tienhoven G, van Veldhuisen E, Wang-Gillam A, Weiss MJ, Wilmink JW, Yamaue H, Homs MYV, van Eijck CHJ, Katz MHG, Koerkamp BG. Neoadjuvant FOLFIRINOX in patients with borderline resectable pancreatic cancer: a systematic review and patient-level meta-analysis JNCI. J Natl Cancer Inst 2019; 111: 782-794.

23. Chawla A, Ferrone C. Neoadjuvant therapy for resectable pancreatic cancer: an evolving paradigm shift. Front Oncol 2019; 9: 1085.

24. Scheufele F, Friess H. Neoadjuvant treatment of primarily resectable and borderline resectable pancreatic cancer. Chirurg 2020; doi: 10.1007/s00104-019-01093-7.

25. Schwarz L, Vernerey D, Bachet JB, Tuech JJ, Portales F, Michel P, Cunha AS. Resectable pancreatic adenocarcinoma neo-adjuvant FOLF(IRIN)OX-based chemotherapy - a multicenter, non-comparative, randomized, phase II trial (PANACHE01-PRODIGE48 study). BMC Cancer 2018; 18: 762.

26. Labori KJ, Lassen K, Hoem D, Grønbech JE, Søreide JA, Mortensen K, Smaaland R, Sorbye H, Verbeke C, Dueland $\mathrm{S}$. Neoadjuvant chemotherapy versus surgery first for resectable pancreatic cancer (Norwegian Pancreatic Cancer Trial-1 (NorPACT-1) - study protocol for a national multicentre randomized controlled trial. BMC Surg 2017; 25: 94.

27. Reni M, Balzano G, Zanon S, Zerbi A, Rimassa L, Castoldi R, Pinelli D, Mosconi S, Doglioni C, Chiaravalli M, Pircher C, Arcidiacono PG, Torri V, Maggiora P, Ceraulo D, Falconi M, Gianni L. Safety and efficacy of preoperative or postoperative chemotherapy for resectable pancreatic adenocarcinoma (PACT-15): a randomised, open-label, phase 2-3 trial. Lancet Gastroenterol Hepatol 2018; 3: 413-423.

28. Sohal S, Gandhi N, Shaalan Beg M, Wang-Gillam A, Lloyd Wade J, Guthrie K, Lowy K, Agop P, Hochster H. SWOG S1505: Initial findings on eligibility and neoadjuvant chemotherapy experience with mfolfirinox versus gemcitabine/nab-paclitaxel for resectable pancreatic adenocarcinoma. J Clin Oncol 2019; 37 (4 Suppl): 414.

\section{Address for correspondence:}

\section{Robert Dziura PhD}

Department of Clinical Oncology

Holy Cross Cancer Centre

ul. Stefana Artwińskiego 3, 25-734 Kielce, Poland

Phone: +48604675 789

E-mail: onko.rdz@gmail.com 